\title{
Die Grafen von Wertheim und ihre Memoria ${ }^{1}$
}

\author{
Von Hermann Ehmer
}

Im Liebighaus in Frankfurt am Main steht im Foyer das Grabmal eines Ehepaars, gearbeitet aus dem am Main heimischen Buntsandstein (Abb. 2). Das Paar ist kniend dargestellt, in Gebetshaltung. Über den Häuptern beiden Personen befindet sich eine „Vronik“ oder „vera ikon“, eine Darstellung des Schweißtuches der Veronika, gehalten von einer Gestalt, vermutlich einem Engel. Für die zeitliche Ansetzung des Grabmals hat sich die Kunstgeschichte nach einigen unterschiedlichen Datierungen schließlich auf das zweite Viertel des 14. Jahrhunderts geeinigt.

Fraglich ist die Identität des Paares. Wenn man sich der eben genannten Datierung anschließt, müssen die dargestellten Personen dem Adel, wohl dem Grafenoder Herrenstand angehören. Sie knien nämlich, wie damals für solche Personen üblich, auf Löwe und Hund. Allerdings trägt der Mann keine Rüstung, wie man es bei Herren dieses Standes erwarten müsste. Das Denkmal zeigt auch keine Wappen, wobei es fraglich bleiben muss, ob es solche nie gegeben hat oder ob sie verloren sind. Lediglich am Boden zwischen den beiden Personen ist eine Rose dargestellt. Ob diese heraldisch zu verstehen und etwa dem Wappen der Grafen von Wertheim ${ }^{2}$ entnommen ist, muss fraglich bleiben.

Eine Hypothese lautet dahingehend, dass hier die Gräfin Elisabeth von Wertheim und ihr Ehemann Gottfried von Hohenlohe dargestellt sind. Elisabeth war die Tochter von Graf Poppo IV. von Wertheim (†1278) und heiratete etwa 1283 Gottfried von Hohenlohe, der am 6. August 1290 an den Folgen eines Jagdunfalls verstarb. Die Sage will, dass die Gräfin selbst, die ein Jagdtier treffen wollte, den Tod ihres Ehemannes verschuldete ${ }^{3}$. Hinzu kam noch, dass der einzige Sohn aus dieser Ehe früh starb. Gräfin Elisabeth selber starb am 6. Februar 1335; sie hat also

${ }^{1}$ Referat bei der Jahrestagung der Kommission für geschichtliche Landeskunde in Baden-Württemberg im Kloster Bronnbach, 28. Juni 2013. Für die Drucklegung wurde der Text wesentlich erweitert und mit Nachweisungen versehen.

${ }^{2}$ Zu diesem vgl. Hermann Ehmer, Die ältesten Siegel der Grafen von Wertheim und die Entstehung des Wertheimer Wappens, in: Aus der Arbeit des Archivars. Festschrift für Eberhard Gönner, hg. von Gregor Richter (Veröffentlichungen der Staatlichen Archivverwaltung Baden-Württemberg, Bd. 44), Stuttgart 1986, S. 407-423.

${ }^{3}$ Gustav Rommel, Elisabeth von Hohenlohe geb. Gräfin von Wertheim (1260-1335) die Gründerin der Kartause Grünau im Spessart, in: Wertheimer Jahrbuch (künftig: WJb) 1951, 
45 Jahre als Witwe zugebracht. In dieser Zeit betätigte sie sich als Wohltäterin und Stifterin, wobei ihre Zuwendungen vor allem dem Deutschen Orden galten, den auch die Hohenloher häufig bedachten. Besonders die Häuser des Deutschen Ordens in Neubrunn, Prozelten, Würzburg und Mergentheim wurden von Elisabeth begabt, ebenso die Klöster in der Umgebung, wie Gerlachsheim, Holzkirchen und Schäftersheim.

Die wohl bedeutendste Stiftung der Gräfin Elisabeth war die Kartause Grünau im Spessart ${ }^{4}$. Durch eine Urkunde vom 15. März $1328^{5}$ übergab die Gräfin den Kartäusern auf dem Michaelsberg in Mainz Dorf und Markung Schollbrunn und andere Güter und Einkünfte. Die Kartäuser gründeten hierauf in der Nähe von Schollbrunn bei dem Hof Grunach oder Grünau, wo sich bereits eine Kapelle befand $^{6}$, die erste rechtsrheinische Kartause.

Es hätte somit nahe gelegen, dass Gräfin Elisabeth Grünau zu ihrem Begräbnis bestimmte. Doch war die Kartause bei ihrem Tod noch keineswegs fertiggestellt. Dies ist daraus zu schließen, dass der Kartause 1335 die Erlaubnis erteilt wurde, an einem Tragaltar Messe zu lesen ${ }^{7}$. Dies bedeutet doch wohl, dass es noch keine Kirche gab, denn erst 1346 genehmigte der Bischof von Würzburg, dass ein Erzbischof oder Bischof die Altäre und den Friedhof in Grünau weihte ${ }^{8}$. Da die Vronik, das Schweißtuch der Veronika, das Wappen der Kartause Grünau ist, könnte daran gedacht werden, dass Bronnbach als vorläufiger Begräbnisort der Gräfin vorgesehen war. Diese Annahme wird dadurch bestärkt, dass die Gräfin im Liber mortuorum des Klosters Bronnbach eingetragen ist ${ }^{9}$. Problematisch ist freilich in diesem Zusammenhang, dass das jetzt im Liebighaus befindliche Grabmal anscheinend auf dem Bronnbacher Friedhof hinter der Kirche abgestellt war und somit für entbehrlich gehalten wurde, so dass man es 1937 nach Frankfurt abgab. Auf den Friedhof war das ursprünglich zweifellos für die Kirche gedachte Grabmal möglicherweise bei der Barockisierung der Bronnbacher Klosterkirche gelangt, weil es wohl schon damals nicht identifizierbar war.

Die Frage des Bronnbacher Grabmals im Frankfurter Liebighaus soll aber hier nicht weiter verfolgt werden. Es soll hier um die Memoria der 1556 ausgestorbenen

S. 33-39; Heidemarie Firmbach-Dassing, Elisabeth von Hohenlohe und die Sage. Die Kartause Grünau, in: WJb 1994, S. 37-51.

${ }^{4}$ Gustav Rommel, Geschichte der ehemaligen Kartause Grünau im Spessart, in: WJb 1932, S. 39-97; WJb 1933, S. 41-74.

${ }^{5}$ Staatsarchiv Wertheim (künftig: StAWt)-G XXV 2.

${ }^{6}$ Notariell beglaubigte Abschrift von vier Urkunden betreffend die Kapelle zu St. Nikolaus und Laurentius in Grünau StAWt-G XXV 1a.

7 StAWt-G XXV 6.

8 StAWt-G XXV 16.

9 J. Kühles (Bearb.), Liber mortuorum Monasterii Brunnbacensis, in: Archiv des historischen Vereines von Unterfranken und Aschaffenburg 21 (1871) S. 91-158, hier S. 99 unter dem 26. Februar 1320: Elisabetha de Wertheim, uxor Godefridi de Hohenlobe. - Dem Abschreiber des Nekrologs ist bei der Jahreszahl also ein Fehler unterlaufen. 
gräflichen Familie von Wertheim gehen ${ }^{10}$. Hierbei sind zwei Elemente der Memoria zu beobachten. Zum einen geht es um Stiftungen für das gottesdienstliche Gedächtnis der Verstorbenen, die heute noch in Urkunden, Nekrologen oder Seelbüchern fassbar sind. Zum anderen geht es um Denkmäler, Grabmäler, Epitaphien und dergleichen, aus Stein oder Holz, also um dingliche Zeugnisse der Memoria. Beide Elemente der Memoria sind einem Traditionsprozess unterworfen. Sie können nicht nur in Vergessenheit ${ }^{11}$, sondern auch in Verlust geraten. Das heißt also, dass wir hier nur von der Memoria handeln können, für die wir heute noch schriftliche oder dingliche Zeugnisse haben. Am einfachsten ist es deshalb, hier den verschiedenen Gedächtnisorten der Grafen von Wertheim nachzugehen, die sich im Laufe der Zeit änderten.

\section{Zisterzienserkloster Bronnbach ${ }^{12}$}

Das erste urkundliche Zeugnis dieses Klosters ist die päpstliche Bestätigungsurkunde von $1153^{13}$. Die Zisterze Bronnbach ist die Stiftung einer Gruppe Adliger, deren Namen in den frühen Urkunden als Billung von Lindenfels, Sigeboto von

10 Allgemein vgl. dazu: Hermann Ehmer, Geschichte der Grafschaft Wertheim, Wertheim 1989; Ders., Grafen von Wertheim, Grafen und Fürsten von Löwenstein-Wertheim, in: Handbuch der baden-württembergischen Geschichte, Bd. 5, Stuttgart 2007, S. 413-419, hier S. 414 f. (Stammtafeln).

${ }^{11}$ Dies gilt in der Tat für das nach Frankfurt abgegebene Grabmal, zumal es nicht erwähnt wird in: Die Kunstdenkmäler des Amtsbezirks Wertheim (künftig: KDM Wertheim) (Kreis Mosbach), bearb. von Adolf von Oechelhäuser, Freiburg i.B. 1896; hier wird auf S. 6-89 das Kloster Bronnbach beschrieben. Als inschriftloses Denkmal war es nicht zu besprechen in: Die Inschriften des badischen Main- und Taubergrundes. Wertheim-Tauberbischofsheim, gesammelt und bearb. von Ernst Cucuel/Hermann Eckert (Die Deutschen Inschriften 1. Bd., Heidelberger Reihe, Bd. 1, künftig: DI 1), Stuttgart 1942. Auch der Jahresbericht des Historischen Vereins Wertheim von Ernst Vollhardt erwähnt die Abgabe des Denkmals nicht, doch ist dies aufgrund der Umstände der Abgabe und angesichts anderer Zeitereignisse durchaus verständlich; Ernst Vollhardt, Jahresbericht des Historischen Vereins Wertheim, in: WJb 1937, S.5-17. Der Verfasser bemerkte das Denkmal bei einem Besuch des Museums am 10. Januar 2010. Ähnlich ging es auch anderen Besuchern des Liebig-Hauses, vgl. daher jetzt: Leonhard Scherg, Das Wanddenkmal eines Ehepaares aus Bronnbach (Taubertal), in: WJb 2008/2009, S.73-90. Das Denkmal wird hier aus kunstgeschichtlicher und historischer Sicht besprochen und vor allem auch die Umstände der Abgabe nach Frankfurt aufgrund noch vorhandener Akten dargestellt.

${ }^{12}$ Leonhard Scherg, Die Zisterzienserabtei Bronnbach im Mittelalter. Studien zur Geschichte der Abtei von der Gründung bis zur Mitte des 14. Jahrhunderts (Mainfränkische Studien, Bd. 14), Würzburg 1976; Peter Müller (Hg.), Kloster Bronnbach 1153-1803. 650 Jahre Zisterzienser im Taubertal, Wertheim ${ }^{2} 2007$. Darin insbesondere: Harald Drös, Kloster Bronnbach als Begräbnis- und Memorialstätte, S. 103-120.

13 Regesten der Urkunden des Klosters 1153-1369 bietet Scherg, Zisterzienserabtei (wie Anm. 12) S. 245-325. Auf diese Regesten wird im Folgenden verwiesen. 
Zimmern und Beringer von Gamburg angegeben werden ${ }^{14}$. Die Klosterchronistik nennt noch Erlebold von Krensheim als weiteren Stifter. Der später ebenfalls genannte Trageboto von Zimmern wird hier offenbar zu Unrecht aufgeführt.

Fest steht hingegen, dass die Grafen von Wertheim nicht zu diesem Kreis zählten, wenn sie auch in verwandtschaftlichen Beziehungen zu einzelnen der Stifter standen. Gleichwohl wird die Eigenschaft der Wertheimer Grafen als Mitstifter Bronnbachs schon Ende des 14. Jahrhunderts behauptet ${ }^{15}$. Immerhin waren sie Wohltäter des Klosters, dem sie bereits in den ersten Jahren seines Bestehens Güter und Einkünfte zuwendeten. Es handelte sich allerdings um für die Grafen zumeist entlegene Stücke, so dass es dabei mehr um Maßnahmen zur Arrondierung des gräflichen Besitzes ging. Alsbald aber gelangen dem Kloster Erwerbungen von den Grafen, von denen wir dadurch Kunde haben, dass es sich um Würzburger Lehen handelte, für deren Veräußerung der Würzburger Bischof seine Genehmigung erteilte. Graf Poppo I. $(† 1212)$ schenkte dem Kloster 1202 Besitz in Dörlesberg. Weitere Grundstücksgeschäfte waren verbunden mit einer Ewiglicht-Stiftung für das Grab Poppos I. und eine consobrina, eine namentlich nicht bekannte Nichte des Grafen. Dieses Grab ist freilich nicht erhalten.

Das Verhältnis des Klosters Bronnbach zu den Grafen von Wertheim verschlechterte sich in der Folgezeit, schließlich stand man hinsichtlich der beiderseitigen Besitzentwicklung in Konkurrenz zueinander. Erst in der zweiten Hälfte des 14. Jahrhunderts erscheinen die Grafen wieder als Wohltäter, 1354 wird Graf Eberhard von Wertheim $(† 1373)$ als Klosterschirmer bezeichnet ${ }^{16}$. Er ist auch im Kloster begraben, sein Grabmal befindet sich im Querschiff ${ }^{17}$ und zeigt den Grafen in Rüstung mit der Fahnenlanze in der Linken, mit der Rechten ein riesiges Vollwappen haltend (Abb. 3). Die Umschrift der überlebensgroßen Grabplatte lautet: Anno $d$ [omi] ni millesimo trecentesimo iii nono kalen[dis] Sept[embris] obiit Eberhard[us] comes de Werthen. Mit der Umschrift ist also die bildliche Darstellung, die einen Grafen von Wertheim zeigt, auf eine bestimmte Person bezogen, da Name und Sterbedatum dieser Person genannt werden. Dazu ist Graf Eberhard im Liber mortuorum des Klosters eingetragen, und zwar unter dem 21. August: Obiit Eberhardus Comes de Wertheim ${ }^{18}$.

${ }^{14} \mathrm{Zu}$ diesem Stifterkreis vgl. den ausführlichen Exkurs bei SCHERG, ebd., S. 229-237. Für die frühen Quellen zur Geschichte des Klosters vgl. den Exkurs bei ScherG, ebd., S. 236245.

${ }^{15}$ Zum Verhältnis der Grafen von Wertheim zum Kloster Bronnbach vgl. Scherg, ebd., S. 32-45.

${ }^{16}$ Scherg, ebd., Regest Nr. 348, S. 323.

17 KDM Wertheim (wie Anm. 11) Nr. 84, S. 72; DI 1 (wie Anm. 11) Nr. 114, S. 60. - Dieses Grabmal soll im Dreißigjährigen Krieg ausgerechnet von einem Grafen von Löwenstein-Wertheim (DI 1 nennt fälschlich einen Grafen Friedrich von Wertheim, den es nie gegeben hat) beschädigt worden sein. Vermutlich ist lediglich das Gesicht des Grafen überarbeitet worden, so dass ein eigenartiges Flachrelief entstand.

18 Kühles (wie Anm. 9) S. 121. 
Im Kloster Bronnbach ist auch Eberhards geistlicher Bruder Poppo begraben, der Propst des Stifts St. Peter und Alexander in Aschaffenburg war. Sein Grabmal ${ }^{19}$ befindet sich im Südflügel des Kreuzgangs. Es zeigt in stark abgetretener Ritzzeichnung eine nur noch schwach zu erkennende männliche Figur. Auch die Umschrift ist abgetreten und weist Fehlstellen auf. Hinsichtlich der Memoria dieses Grafen von Wertheim gilt dasselbe, wie für seinen eben genannten Bruder. Im Totenbuch des Klosters ${ }^{20}$ erscheint Poppo unter dem 28. April 1374 als Generosus D. Boppo Comes de Wertheim. Das Prädikat generosus, das ihm beigelegt wurde, ist wohl nicht als Standesbezeichnung zu verstehen, denn sonst hätte es auch seinem Bruder gebührt. Es ist hier vermutlich im Sinne von „edelmütig“, „hochherzig“ zu verstehen. Offenbar hatte das Kloster Anlass, dieses Grafen in besonderer Weise zu gedenken, wenngleich wir auch nicht wissen, welche Wohltaten das Kloster Propst Poppo zu verdanken hatte ${ }^{21}$.

Der Brauch der Bestattung im Kloster Bronnbach wurde danach von der gräflichen Familie offenbar nicht mehr fortgesetzt. Gleichwohl ist zu vermerken, dass sich auch noch Graf Johann III. von Wertheim im Nekrolog des Klosters fin$\operatorname{det}^{22}$, und zwar unter dem 25. Mai 1497: Obiit generosus D. Comes Joannes de Wertheim. Ob dieser Graf freilich in Bronnbach bestattet wurde, ist - wie weiter unten ausgeführt werden wird - zu bezweifeln. Sollte das tatsächlich nicht der Fall sein, würde auch die Frage des Begräbnisses der oben genannten Gräfin Elisabeth in einem anderen Licht erscheinen. Dessen ungeachtet ist festzustellen, dass die auf die Grafen Eberhard und Poppo folgende Generation sich eine neue Grablege geschaffen hatte.

\section{Kartause Grünau}

Die 1328 erfolgte Stiftung der Gräfin Elisabeth von Wertheim wurde 1333 durch Bruder Clarus, Prior der Grande Chartreuse, und das Generalkapitel als Nova Cella prope Grünau, als Neuenzell dem Orden inkorporiert ${ }^{23}$. Die Frage, ob Gräfin Elisabeth dort begraben ist, wurde bereits erörtert. Ihre Stiftung erhielt alsbald namhafte Zustiftungen, so den Pfarrsatz in Eichel und die Kapelle in Hasloch, die der Kartause 1336 durch Graf Rudolf III. (†1355) übereignet und ihr 1373 durch Papst Gregor XI. inkorporiert wurden ${ }^{24}$.

19 KDM Wertheim (wie Anm. 11) Nr. 32, S. 65; DI 1 (wie Anm. 11) Nr. 115, S. 60.

20 Kühles (wie Anm. 9) S. 121.

${ }^{21} \mathrm{Zu}$ den beiden gräflichen Grabmälern vgl. Drös (wie Anm.12) S. $109 \mathrm{f}$.

22 Kühles (wie Anm. 9) S. 111.

23 StAWt-G XXV 4a.

${ }^{24}$ StAWt-G XXV 6a und 8. 
Der Prior zu Grünau anerkannte 1359 die Guttaten der Grafen von Wertheim für die Kartause und besonders der Gräfin Katharina und des Grafen Eberhard ${ }^{25}$. Die 1376 verstorbene Gräfin Katharina ist auch in Grünau begraben, während deren Ehemann, wie bereits erwähnt, in Bronnbach seine letzte Ruhestätte fand. Eine stark abgetretene Grabplatte für die Gräfin ist in Grünau erhalten mit der Inschrift:

[†] AN[N]O DO[MINI] M.CCCLX.VI. XIII. K[A]L. MARC[II] O[BIIT] DO[MI]NA KATh[ARINA] COMITISSA [DE WERTHEIM] ${ }^{26}$

Gräfin Katharina ist das einzige bekannte Mitglied der gräflichen Familie von Wertheim, das in der Kartause Grünau begraben wurde. Ansonsten scheint die Kartause vor allem niederadlige Wohltäter gehabt zu haben, wie aus den noch erhaltenen Grabmälern zu schließen ist. Genaueres lässt sich freilich aus Mangel eines Nekrologs nicht sagen.

\section{Stiftskirche Wertheim}

Die Erhebung der Wertheimer Kirche zur Stiftskirche 1481 markiert das Ende einer längeren Entwicklung ${ }^{27}$. Die Stadtgründung Wertheim gehörte wie das untere Taubertal zur „Urpfarrei“ Reicholzheim. Die neu gegründete Stadt hatte eine Marienkapelle ${ }^{28}$ als geistliches Zentrum. Ein 1233 erwähnter Vicepleban daselbst belegt Tendenzen zur Verselbständigung dieser Kirche. Drei Ablassbriefe aus dem Jahre 1295 sind als Hinweise auf größere Bauarbeiten zu werten ${ }^{29} .1379$ veranlasste Graf Johann I. (1372-1407) die Inkorporation der Pfarrei Wertheim-Reicholzheim in das Kloster Bronnbach, wobei er sich sein Präsentationsrecht für die Stelle des

25 Wilhelm Engel (Bearb.), Urkundenregesten zur Geschichte der kirchlichen Verwaltung der Grafschaft Wertheim 1276-1499 (Sonderveröffentlichung des Historischen Vereins Wertheim e.V.), Wertheim 1959, Nr. 41, S. 25.

${ }^{26}$ Diese Lesung bietet Erich LANGguth, Jahresbericht für 1952, in: WJb 1952, S. 5-19, hier S. 11. - Danach Heinz-Peter Mielke, Die Inschriften der Kartause Neuzell oder Grünau im Südspessart, in: WJb 1977/78, S. 53-59, hier Nr.3, S. 56.

27 Hermann Ehmer, Die Stifter der Wertheimer Stiftskirche, in: WJb 1984/85, S. 13-30. - Ausführlich zur Vorgeschichte: Peter RüCKeRT, Von der Burgkapelle zur Stiftskirche. Anfänge der Wertheimer Kirchengeschichte, Wertheim 2007. - Die urkundliche Überlieferung ist verzeichnet von ENGEL (wie Anm. 25). - Beschreibung des Baus: KDM Wertheim (wie Anm.11) S. 246-269. - Zur Grablege zusammenfassend: Judith Wipfler, Der Chor der Wertheimer Stiftskirche als herrschaftliche Grablege. Die Epitaphien der Regenten bis ins frühe 17. Jahrhundert, in: WJb 1996, S. 87-178.

${ }_{28}$ Nicht zu verwechseln mit der heutigen Marienkapelle in der Kapellengasse, die anstelle einer 1447 zerstörten Synagoge errichtet wurde.

${ }^{29}$ Druck des ursprünglichen Ablassbriefs, Rom 1295, bei Joseph Asснвасн, Geschichte der Grafen von Wertheim von den ältesten Zeiten bis zu ihrem Erlöschen im Mannesstamme im Jahre 1556, Teil 1-2, Frankfurt a.M. 1843. Hier Teil 2: Wertheimisches Urkundenbuch, Nr.53, S. 57f. Ein zweiter, gleichzeitiger Ablassbrief kam aus Anagni, beide wurden vom Bischof von Würzburg bestätigt und vermehrt; vgl. RücKERT (wie Anm. 27) S. 16. 
vicarius perpetuus in Wertheim vorbehielt ${ }^{30}$. Vier Mönche sollten für den Gottesdienst in Wertheim sorgen. Diese für ein Zisterziensterkloster ungewöhnliche Bestimmung hielt nicht lange vor, sondern erfuhr schon 1383/84 eine Änderung. Es wurden Pfründen für vier Weltgeistliche geschaffen, so dass neben dem Vicarius sechs weitere Altarpfründen errichtet wurden ${ }^{31}$. Der Vicarius war damit der oberste der insgesamt zehn Kleriker an der Wertheimer Kirche.

Am 14. Juli 1379 hatte Graf Johann I. von dem päpstlichen Legaten Pileus in Mergentheim einen umfassenden Ablassbrief für die Wertheimer Pfarrkirche St. Marien erlangt ${ }^{32}$. Dieser Ablass ist als Vorbereitung für ein größeres Bauwesen zu verstehen, das 1384 begonnen wurde. Dokumentiert ist der Neubau der Wertheimer Kirche durch eine Inschrift über dem kleinen Nordportal, die in Gestalt eines Grabdenkmals gehalten ist (Abb.4). Der Stein zeigt das Wertheimer Wappen mit der Inschrift am Rand:

Anno dni MCCCLXXXIIII an Sant Johanns tage des Teuffers haben wir Johans Grave czu Wertheim angehaben dis nuwe Werke in Ere Gottes. ${ }^{33}$

Der Namenstag des Grafen wurde als Tag des Baubeginns gewählt, die Bauinschrift hatte somit Memorialfunktion. Doch nicht nur dies. Graf Johann I. als Stifter wurde auch in der Mitte des Chors bestattet. Die Stelle wurde durch ein Hochgrab markiert, dessen Deckplatte jetzt an der nördlichen Chorwand angebracht ist ${ }^{34}$. Sie zeigt den Grafen mit Fahnenlanze, Wappen und Helm (Abb. 1). An den vier Ecken sind Wappen angebracht, nämlich Wertheim, Breuberg, Hohenzollern (Burggraf von Nürnberg) und Kärnten. Es sind dies die vier großelterlichen Wappen, die die Abstammung des Grafen aufzeigen:

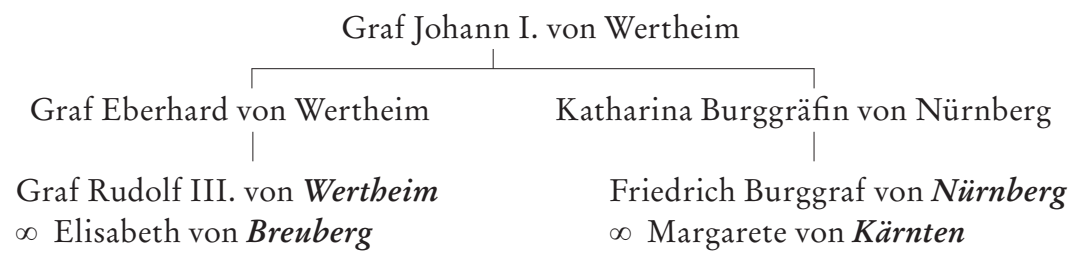

Damit nicht genug: an den Stifter der Kirche erinnert auch ein überlebensgroßes Denkmal an der Nordwand des Chors, das allerdings schriftlos ist. Es zeigt unter einem von Fialen begleiteten, krabbenverzierten Dreiecksgiebel den Grafen Johann I. und seine beiden Frauen Margarete von Rieneck und Uta von Teck, beide auf Hunden stehend (Abb. 5). In der Mitte ist der Graf zu sehen, auf einem Löwen stehend, in Rüstung, mit dem Wertheimer Wappen auf der Brust mit der in den Drei-

\footnotetext{
30 Ascнвасн, Urkundenbuch (wie Anm. 29) Nr. 118f., S. 151-155.

31 StAWt-R US.

32 Engel (wie Anm. 25) Nr. 64, S. 41.

33 KDM Wertheim (wie Anm. 11) S. 246; DI 1 (wie Anm. 11) Nr. 5.

34 KDM Wertheim (wie Anm. 11) Nr. 1, S. 257; DI 1 (wie Anm. 11) Nr. 120, S. 62.
} 
Abb. 1: Deckplatte eines Hochgrabs für Graf Johann I. von Wertheim (†1407), seit 1611 an der Nordwand des Chores der Wertheimer Stiftskirche (Vorlage: Inschriftenkommission der Heidelberger Akademie der Wissenschaften). [Die Abbildung kann aus rechtlichen Gründen online nicht bereitgestellt werden.] 
ecksgiebel hineinragenden Fahnenlanze in der Rechten. Links (vom Beschauer) seine erste Frau Margarete von Rieneck, rechts die zweite Frau Uta von Teck. Alle drei Personen sind mit ihren jeweiligen Wappen über den Köpfen eindeutig identifiziert ${ }^{35}$. Des Stifters der Stiftskirche ist also an und in der Kirche dreifach gedacht!

Graf Johann I. († 1407) hatte eine Erbteilung verfügt ${ }^{36}$, wonach der ältere Sohn Johann II. (1407-1444) die Grafschaft Wertheim erhielt, der Sohn aus der zweiten Ehe, Michael I. (1407-1440), die Herrschaft Breuberg, die Rudolf III. (†1355), der Großvater Johanns I., erheiratet hatte.

An der Stiftskirche in Wertheim wurde auch unter Johann II. weiter gebaut. Von seinem Stiefonkel, dem aus dem Hause Teck stammenden Patriarchen Ludwig von Aquileja (†1439), erlangte Johann II. 1439 zwei Ablässe für Wertheim, wovon der eine für die Stiftskirche, der andere für die Bruderschaft von Priestern und Laien an dieser Kirche bestimmt war ${ }^{37}$. Offensichtlich wurde nun der Turm der Kirche gebaut, denn dieser zeigt am dritten Geschoss - und somit von unten nur mit Mühe zu erkennen - vier Ahnenwappen des $\mathrm{Grafen}^{38}$ :

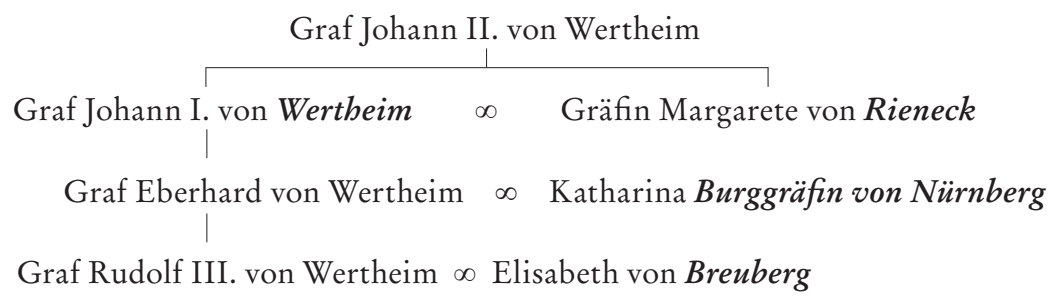

Die Asymmetrie dieser Darstellung darf nicht irritieren ${ }^{39}$. Da der Ahnennachweis bis in die Urgroßelterngeneration zurückgeht, genügte es, neben dem Stammwappen die Wappen der Frauen, der Mutter, Großmutter und Urgroßmutter, aufzunehmen. Diese drei Generationen zurückreichenden Wappen weisen die Stiftskirche mit ihrem mächtigen Turm als Familienprojekt der Grafen von Wertheim aus, stellen die einzelnen Familienmitglieder in die die Zeiten übergreifende Gemeinsamkeit hinein und gewährleisten damit deren Gedächtnis.

35 KDM Wertheim (wie Anm. 11) Nr. 3, S. 257 f.

${ }^{36}$ Es handelt sich um das sogenannte Hausstatut Johanns I. von 1398, wonach es künftig zwei regierende Herren von Wertheim geben sollte. Asснвасн, Urkundenbuch (wie Anm. 29) Nr. 124, S.163-168. Dazu: Ehmer, Geschichte (wie Anm. 10) S. 62-64.

37 Engel (wie Anm. 25) Nr.213f., S. 109.

38 KDM Wertheim (wie Anm. 11) S. 247 f.; Abbildung in: Ehmer, Stifter (wie Anm. 27) S. 27.

39 Ein besonders auffallendes Beispiel für eine solche Asymmetrie: Hermann EHMER, Die Ahnenprobe der Gräfin Dorothea von Wertheim geb. von Rieneck auf ihrem Grabmal in Grünsfeld, in: Mainfränkisches Jahrbuch für Geschichte und Kunst 41 (1989) S. 169-182. Der Ahnennachweis reicht hier - in wohlbedachter Auswahl - nicht weniger als sechs Generationen zurück. 
Neben den Denkmälern, soweit noch vorhanden, sind selbstverständlich auch die frommen Stiftungen zu erwähnen, die zum Seelenheil der gräflichen Familie gemacht wurden und die deren gottesdienstliches Gedächtnis für alle Zeiten sichern sollten. 1346 hatten Graf Rudolf und seine Ehefrau Elisabeth eine Stiftung für ihr und ihrer Vorfahren Seelenheil gemacht ${ }^{40} .1360$ errichteten Graf Eberhard und Gräfin Katharina eine Stiftung für die Wertheimer Pfarrkirche zu ihrem und ihrer Nachkommen Seelenheil ${ }^{41}$. Diesen folgten zahlreiche weitere Stiftungen ${ }^{42}$, die schließlich offenbar unübersichtlich wurden, so dass Graf Johann II. 1410 mit Bezugnahme auf die Stiftungen seines Großvaters und seines Vaters einen gemeinsamen Jahrtag für alle Mitglieder des Grafenhauses festlegte ${ }^{43}$. Demnach scheint es für die Stiftskirche keinen Nekrolog gegeben zu haben, wenigstens ist kein solcher überliefert. Der gemeinsame Jahrtag sollte an jeder Goldfasten, somit alle Vierteljahre gehalten werden, und zwar mit einer gesungenen Messe mit zwei Chorröcken, mit Vigil und Messe, mit sechs aufgesteckten Kerzen und dazugehörigen Gebeten.

Johann II. erließ 1419 zusammen mit seinem Bruder Michael I. (1407-1440) und seinem Sohn Georg I. (1444-1454) und ihren namentlich genannten Ehefrauen eine Ordnung der Pfründen und des Gottesdienstes an der Wertheimer Pfarrkirche als der Grablege ihrer Voreltern ${ }^{44}$. Pfarrer und elf Vikare haben täglich Messe und die Tagzeiten zu singen. Hierfür stiftete die gräfliche Familie eine tägliche Präsenz. Die Ordnung wurde vom zuständigen Bischof von Würzburg im Wesentlichen bestätigt ${ }^{45}$. Hierbei zeigt es sich, dass das Kloster Bronnbach in der Stiftskirche immer noch beteiligt war, denn es hatte ein Drittel der jeweils fälligen Abgaben an Bischof und Papst zu tragen.

Diese Ordnung ist als Vorstufe zu der 1481 durch Papst Sixtus IV. auf Bitten von Graf Johann III. verfügten Erhebung der Wertheimer Pfarrkirche zur Stiftskir$\mathrm{che}^{46} \mathrm{zu}$ werten. Der Pfarrer wurde nun Dekan des Stiftskapitels, die Wertheimer Kirche hatte somit einen, ihrer Bestimmung als Grablege des Grafenhauses angemessenen Rang erhalten. Ein Grabmal für Graf Johann II. ist nicht bekannt, dafür aber eines für seinen Bruder Michael I. (1407-1440) ${ }^{47}$, den Stammvater der jüngeren, Breuberger Linie der Grafen von Wertheim (Abb. 10). Somit blieb die Wertheimer Stiftskirche Begräbnisort auch für diese Linie, fast bis zu ihrem Ende. Hierher gehört Graf Wilhelm I. (1440-1482), Sohn und Nachfolger Michaels I., für den

40 Engel (wie Anm. 25) Nr.21, S. 13.

${ }^{41}$ Engel (wie Anm. 25) Nr. 47, S. 29.

42 So 1373 durch Graf Eberhard, seine Ehefrau Gräfin Katharina und ihrem Sohn Johann; EnGEL (wie Anm. 25) Nr. 62, S. 40. - 1382 erfolgten zwei Stiftungen durch Graf Johann und Gräfin Margarete; Engel (wie Anm. 25) Nr. 66f., S. 142.

43 Engel (wie Anm. 25) Nr. 109, S. 61.

44 Engel (wie Anm. 25) Nr. 138, S. $74 \mathrm{f}$.

45 Engel (wie Anm. 25) Nr.139, S. 75 f.

46 Engel (wie Anm. 25) Nr. 356, S. 174.

47 KDM Wertheim (wie Anm. 11) Nr. 15, S. 264; DI 1 (wie Anm. 11) Nr. 138, S. 68. 


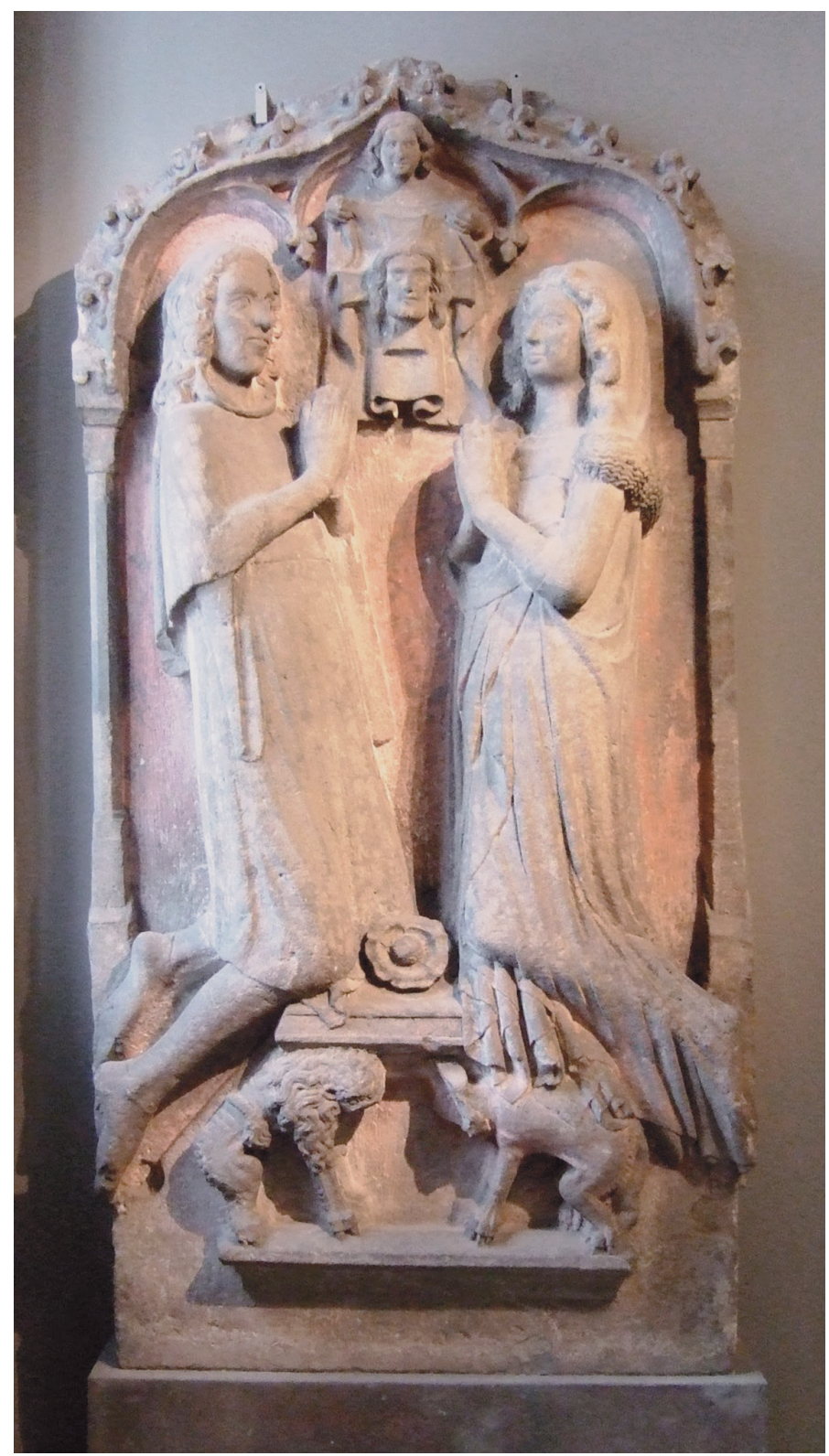

Abb. 2: Grabmal eines unbekannten Ehepaars.

Aus dem Kloster Bronnbach, seit 1937 im Frankfurter Liebighaus (Foto: Ehmer). 
Abb. 3: Grabplatte des Grafen Eberhard I. von Wertheim († 1373) in der Kirche des Klosters Bronnbach (Vorlage: Inschriftenkommission der Heidelberger Akademie der Wissenschaften).

[Die Abbildung kann aus rechtlichen Gründen online nicht bereitgestellt werden.] 


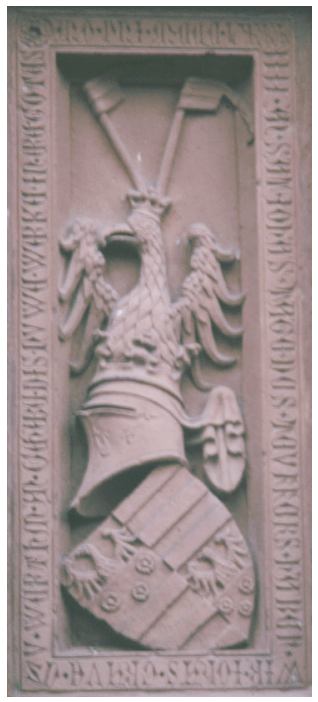

Abb. 4: Bauinschrift an der Nordseite der Stiftskirche in Wertheim von 1384 (Foto: Rückert).

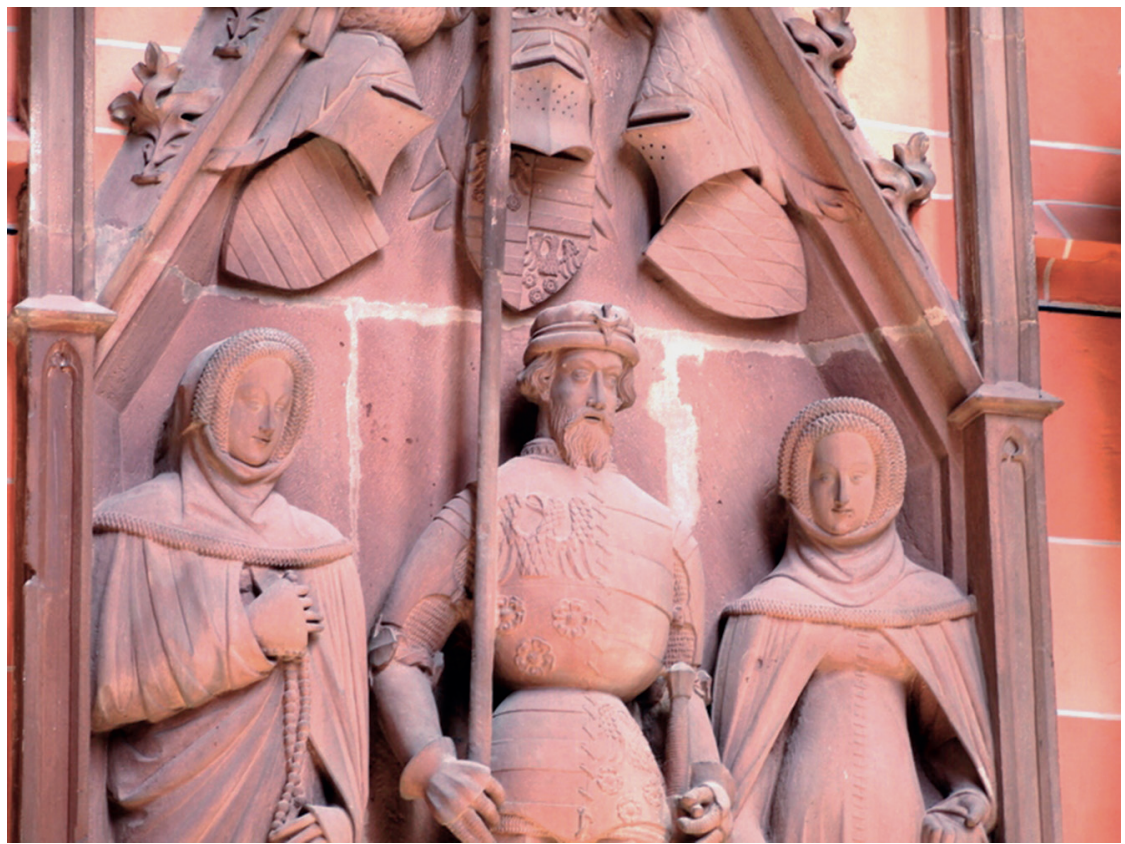

Abb. 5: Stifterdenkmal an der Nordwand des Chores der Wertheimer Stiftskirche, das Graf Johann I. und seine beiden Frauen Margarete von Rieneck und Uta Herzogin von Teck zeigt (Foto: Ehmer). 
Abb. 6: Totenschild für Graf Asmus von Wertheim († 1509).

Ursprünglich in der Stiftskirche Wertheim, jetzt im Grafschaftsmuseum Wertheim

(Vorlage: Wertheimer Jahrbuch 1957, Titelbild).

Abb. 7: Grabmal des letzten Wertheimer Grafen Michael III. († 1556) in der Kirche in Sandbach/Odenwald (Vorlage aus: Kirchen im Breuberger Land. Sandbach, Wald-Amorbach, Höchst 1992, S. 74).

Abb. 8: Disputation zwischen Dr. Johannes Lange von Wetzlar und dem geistlichen Grafen Johann von Wertheim († 1433). Einzelblatt, vermutlich aus dem Compendium des Johannes Lange, im Besitz des Grafschaftsmuseums Wertheim (Vorlage aus: Wertheimer Jahrbuch 1924, Titelbild).

Abb. 9: Wappen des Grafen Asmus von Wertheim († 1509) aus einem Reisemessbuch im Besitz der Ungarischen Nationalbibliothek Budapest (Vorlage: Faksimileausgabe, Budapest 1989, Bl 1').

[Die Abbildungen können aus rechtlichen Gründen online nicht bereitgestellt werden.] 


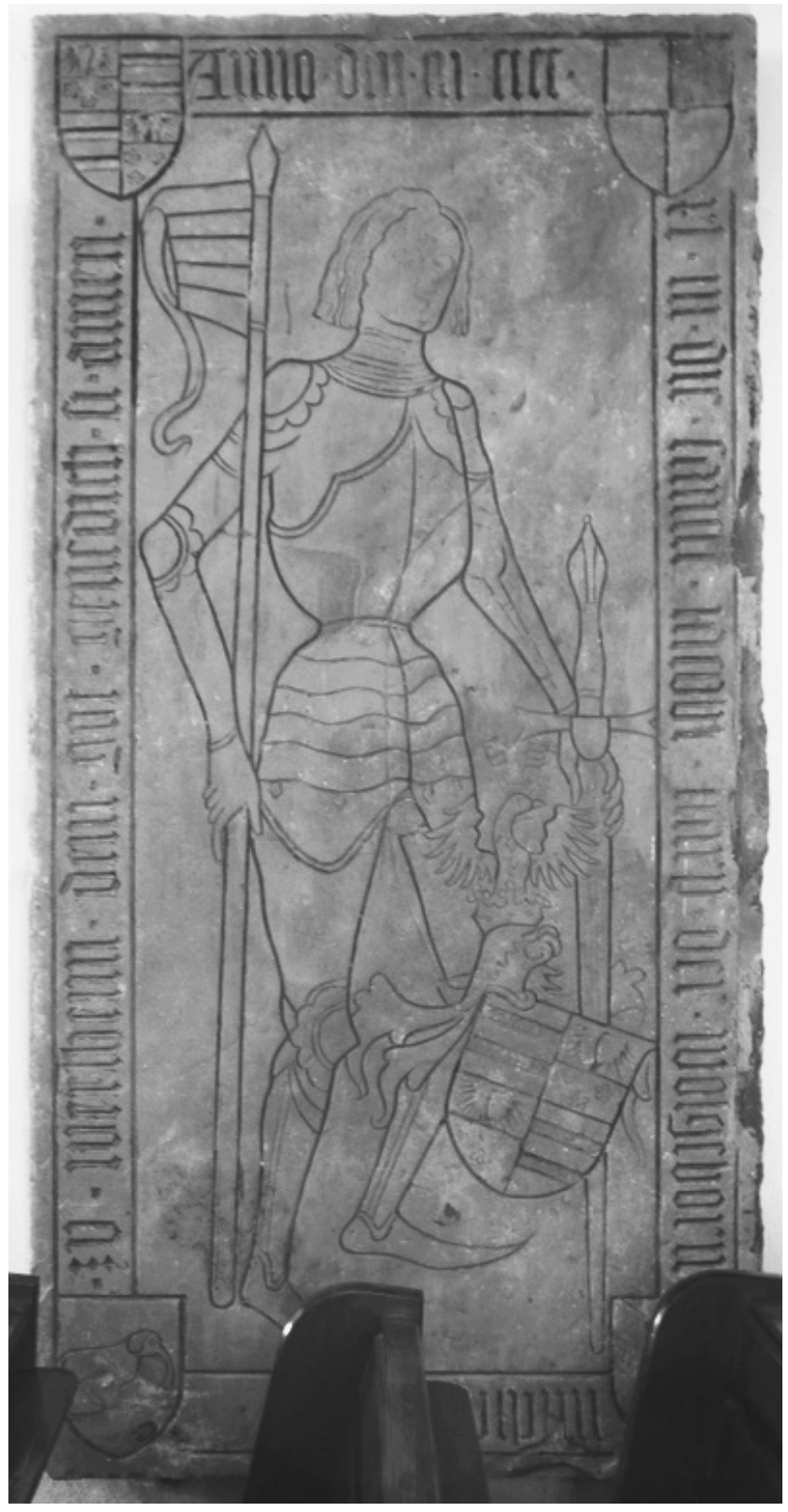

Abb. 10: Grabplatte für Graf Michael I. von Wertheim (†1440) an der östlichen Wand des Schiffs der Stiftskirche Wertheim (Foto: Ehmer). 
ein Totenschild aus der Stiftskirche erhalten ist ${ }^{48}$. Es ist wohl nicht daran zu zweifeln, dass es ursprünglich auch ein Epitaph für den Grafen gab.

Graf Johann III. (1454-1497), der letzte der Wertheimer Hauptlinie, hatte ursprünglich die geistliche Laufbahn eingeschlagen und war Domherr in Köln. Als aber 1447 der ursprünglich vom Vater, Graf Georg I., für die Nachfolge bestimmte Sohn Eberhard starb, wurde Johann laisiert. Er trat dann 1454 in Wertheim die Regierung an. Er blieb unverheiratet ${ }^{49}$, so dass mit ihm die Wertheimer Hauptlinie endete. Bei der Renovierung der Stiftskirche 1957 wurde ein stark abgetretenes Grabmal aufgefunden, dessen Bedeutung wegen des schlechten Erhaltungszustands nicht sofort erkannt und das deshalb zerschlagen wurde. Immerhin ist ein Foto dieses Grabmals erhalten, das die Identifizierung nachträglich ermöglichte ${ }^{50}$. Damit ist der Beweis erbracht, dass Johann III. in der Wertheimer Stiftskirche bestattet wurde und nicht etwa im Kloster Bronnbach, wie der Eintrag im oben erwähnten Bronnbacher Totenbuch vermuten lässt.

Auch weiterhin fanden Angehörige der Breuberger Linie ihre letzte Ruhestätte in der Wertheimer Stiftskirche. So Graf Erasmus oder kurz Asmus $(\dagger 1509)^{51}$, ein Sohn des Grafen Wilhelm. Da sein älterer Bruder Michael II. (1482-1531) zur Regierung bestimmt war, wurde Asmus geistlich und war Kanoniker in Aschaffenburg. Diese Laufbahn behagte ihm offensichtlich nicht, denn er ließ sich in den Laienstand versetzen. Da sich Michael II. nicht zu einer Teilung der Herrschaft verstehen konnte, setzte er dem Bruder ein Leibgeding aus. Dieser verheiratete sich daraufhin mit der verwitweten Landgräfin Dorothea von Leuchtenberg, einer Tochter des Grafen Philipp d.Ä. von Rieneck, die die Herrschaft Grünsfeld mit Lauda innehatte. Graf Asmus hatte somit Anteil an der Regierung der Herrschaft und dokumentierte dies auch bei der Erbauung des Oberen Tors in Lauda 1497, das sein Wappen und seinen Namen trägt ${ }^{52}$. Das Paar hatte die Grünsfelder Kirche zum Begräbnis erwählt. Sie stifteten daher einen Ölberg, eine Totenleuchte und

48 DI 1 (wie Anm. 11) Nr. 167, S. 76.

$49 \mathrm{Ob}$ dies darauf zurückzuführen ist, dass Graf Georg und sein Sohn 1448 in die Bruderschaft der Minimi aufgenommen wurden, Asснвасн, Geschichte (wie Anm.29) Teil1, S. 250, Anm. 1, ist zu bezweifeln. Es kann sich eigentlich nur um die Mitteilung der Verdienste des damals in Gründung befindlichen Ordens des Franz von Paula handeln, nicht um Übernahme der asketischen Verpflichtungen, dieser der franziskanischen Ordensfamilie angehörenden Gemeinschaft.

50 Erich LANGGUTH, ... cuius anima requiescat in pace. Grabplattenfunde und Totengedächtnis in der Wertheimer Stiftskirche, in: WJb 2003, S. 15-44, hier S. $28 \mathrm{f}$.

51 Hermann Ehmer, Graf Asmus von Wertheim (1453?-1509) - Ein Lebensbild, in: Beiträge zur Erforschung des Odenwaldes und seiner Randlandschaften, Bd. 5, hg. von Winfried WaCkERFuss, Breuberg-Neustadt 1992, S. 151-184.

52 Die Kunstdenkmäler des Amtsbezirks Tauberbischofsheim (künftig: KDM Tauberbischofsheim) (Kreis Mosbach), bearb. von Adolf von OechelhäUser, Freiburg i.B. 1898, S. 103; DI 1 (wie Anm. 11) Nr. 23, S. 26. 
eine Michaelskapelle auf den Friedhof bei der Kirche. Erhalten ist die Totenleuchte, deren Inschrift das gräfliche Paar als Veranlasser nennt ${ }^{53}$.

Nachdem mit Johann III. 1497 die Wertheimer Hauptlinie der Grafen ausgestorben war, konnte Asmus mit Berufung auf das Hausstatut von 1398 einen Anteil am Erbe einfordern, so dass ihm sein Bruder Michael die Herrschaft Freudenberg als neue Wertheimer Sekundogenitur einräumen musste. Nachdem sich Asmus schon in der Herrschaft Grünsfeld an Bauten verewigt hatte, tat er dies auch in Freudenberg, wo das Rathaus von 1499 seinen Namen trägt ${ }^{54}$. Auch auf der Burg Freudenberg betätigte sich Asmus als Bauherr, wo das große Eingangstor das Wertheimer Wappen und die Jahreszahl 1499 trägt $^{55}$. Dieser Bau muss daher zusammen mit anderen Baumaßnahmen, wie der Verstärkung der Zwingermauer und der Anlegung der Vorburg, auf Asmus zurückgehen.

Mit seiner Gemahlin Dorothea von Rieneck geriet Asmus in Ehestreitigkeiten, ganz offensichtlich wegen der Erbfolge in der Herrschaft Grünsfeld, die dem Sohn Dorotheas aus erster Ehe zugedacht war. Dorothea starb 1503. Sie wurde in der Grünsfelder Kirche begraben, wo das Tilman Riemenschneider zugeschriebene Grabmal an sie erinnert ${ }^{56}$. Graf Asmus starb 1509. An ihn erinnert ein aus der Stiftskirche Wertheim stammender Totenschild ${ }^{57}$ (Abb. 6). Er dürfte deshalb auch in dieser Kirche begraben sein. Obwohl er bemüht war, in seinen Herrschaften sein Gedächtnis auf die Nachwelt zu bringen, ist es ihm - natürlich auch aus Mangel an eigenen, legitimen Nachkommen - nicht gelungen, einen entsprechenden Gedächtnisort zu schaffen.

Graf Michael II., der 1497 den Hauptteil des Wertheimer Erbes übernahm, blieb zeitlebens auf dem Breuberg. Von 1509 an überließ er die Regierung der Grafschaft Wertheim seinem Sohn Georg II. (†1530). Durch und mit Graf Georg II. endet plötzlich und endgültig das gottesdienstliche Gedächtnis der Grafen von Wertheim in der Wertheim Stiftskirche. Er erließ nämlich im Sommer 1518 ein Mandat gegen die Leichenbegängnisse ${ }^{58}$. Dieser Text, mit dem der Graf den Weg zur Einführung der Reformation beschritt, lautet:

Wir werden an unserm abscheide am letztn gericht nit gefragt, ob wir solemniter nach alter gewonheit unser vordern begraben, auch uns selbst mit selgereden, opffern, begrebnus, glockenleuten und andern zubeghen verschafft, wievil jartag und ewige gedechtig wir gestiefft, in welche Bruderschafft wir geschryben, ob auch uns diselbigen oder andere betschafft bestreichen. Aber wir werden mussen rechen-

${ }^{53}$ KDM Tauberbischofsheim (wie Anm. 52) S. 44; DI 1 (wie Anm. 11) Nr. 513, S. 186.

${ }^{54}$ KDM Wertheim (wie Anm. 11) S. 111; DI 1 (wie Anm. 11) Nr. 24, S. 26.

55 KDM Wertheim (wie Anm. 11) S. 108.

${ }^{56}$ KDM Tauberbischofsheim (wie Anm.52) Nr.2, S.40f.; DI 1 (wie Anm.11) Nr.197, S. 84.

57 DI 1 (wie Anm. 11) Nr. 199, S. 84 f.

${ }^{58}$ Hermann Ehmer, Recuperati Evangelii Defensor et Instaurator. Die reformatorischen Ordnungen und Mandate des Grafen Georg II. von Wertheim, in: Würzburger Diözesangeschichtsblätter 42 (1980), Festschrift für Hermann Hoffmann, S. 215-234, hier S. 228. 
schafft geben, wievil unserm negsten in nodten geholffen, dan got wil die erbarmung und nit das opffer und diverstendnus mehr dan das opffer. [Hos. 6,6] Darumb liebe frome mentschen verlossend in diser deurung das geprenge und gemelte unnodturfftige costung und komet mher zu hilf armen leuten, brudern und schwestern. Der hoffartig pracht erhept und ursacht die sunde, aber das almusen dilgt die sunde. [Sir. 10,15 / Tob. 12,9]

Mit der Teuerung wird hier ein aktuelles Problem angesprochen. Darüber hinaus zeigt sich ein reformatorischer Impuls, der deutlich auf den Einfluss der 95 Thesen Martin Luthers zurückgeht, die um diese Zeit noch kein ganzes Jahr alt waren. Es handelt sich hier um nichts anderes als die Umsetzung dieser Thesen, die das Problem des Ablasses - für Lebende und Tote - behandeln. Insbesondere geht es hier um die 83. These: „Item: Cur permanent exequia et anniversaria defunctorum, et non reddit aut recipi permittit [Papa] beneficia pro illis instituta, cum iam sit iniuria pro redemptis orare. ${ }^{\text {59 }}$ Das Mandat des Grafen Georg verknüpft diese Aussage mit anderen, etwa mit der 43. These: „Docendi sunt christiani, quod dans pauperi aut mutuans egenti melius facit, quam si venias redimeret. ${ }^{“ 60}$ Diese Betonung der Nächstenliebe gegenüber dem Totengedächtnis ist also unmittelbar aus den Thesen übernommen, während die in freien Zitaten deutliche Berufung auf alttestamentliche Stellen eigenes biblisch-theologisches Nachdenken des Grafen belegt. Schließlich wird man diese Verlautbarung ihm persönlich zuschreiben müssen, zumal diese Absage an das gottesdienstliche Totengedächtnis von größter Tragweite war, da sie den jahrhundertelang geübten Bräuchen ein Ende setzte.

Diese Maßnahme galt sicher nicht nur für die Untertanen, sondern auch für die gräfliche Familie selbst. Das Stiftskapitel hatte somit eine wesentliche Aufgabe verloren. Mindestens drei der Stiftsherren schlossen sich der Reformation an und erhielten Pfarr- oder Predigerstellen auf den Dörfern ${ }^{61}$. Graf Georg führte in der Folgezeit die Reformation in der Grafschaft ein; als entscheidendes Jahr für diese Veränderungen lässt sich 1524 benennen. Es braucht hier keine Reformationsgeschichte der Grafschaft geboten zu werden ${ }^{62}$, doch es leuchtet ein, dass durch die Gemengelage der Rechte diese Veränderungen nicht sofort und vollständig durch-

${ }^{59}$ D. Martin Luthers Werke. Kritische Gesamtausgabe, Bd. 1, Weimar 1883, S. 233-238. Übersetzung nach Heinrich FauseL, D. Martin Luther. Leben und Werk 1483 bis 1521, München/Hamburg 1966, S. 100: „Ferner: Warum bleiben die Leichenbegängnis- und Jahresfeiern für die Verstorbenen immer noch bestehen, und warum gibt der Papst nicht alle Pfründen zurück oder erlaubt die Zurücknahme der für die Toten gestifteten Gelder, wenn es doch Unrecht ist, für die schon Erlösten noch zu beten?“

60 Übersetzung von Fausel (wie Anm. 59) S. 95: „Lehren muß man die Christen: Wer dem Armen gibt oder dem Bedürftigen leiht, tut besser, als wenn er Ablaß löst.“

${ }^{61}$ Ehmer, Geschichte (wie Anm. 10) S. 109.

62 Siehe dazu Ehmer, Geschichte (wie Anm. 10) S.103-112. Erich Langguth, Zur Reformationsgeschichte der Grafschaft, in: DERs., Aus Wertheims Geschichte (Veröffentlichungen des Historischen Vereins Wertheim, Bd. 7), Wertheim 2004, S. 74-83. 
gesetzt werden konnten. Immerhin hatte der Graf seit 1525/26 mit Johann Eberlin von Günzburg einen namhaften Theologen an seiner Seite ${ }^{63}$.

Graf Georg starb 1530, noch vor seinem Vater Michael II. Selbstverständlich erinnert ein Grabmal in der Wertheimer Stiftskirche an ihn. In diesem Grabmal bildet sich der Wandel ab, den der Graf durch die Abschaffung des gottesdienstlichen Totengedächtnisses und die Einführung der Reformation bewirkt hatte. Es handelt sich um ein Schriftgrabmal, mit dem nach den Bearbeitern des Inschriftenwerks „Renaissance und Humanismus in Wertheim“ Einzug gehalten haben ${ }^{64}$. Beim Text des Grabmals handelt sich um nichts weniger als eine Lobrede auf den Toten, genannt wird auch der Name des Stifters des Grabmals, der Sohn Michael III. Es werden also nicht nur Name und Todesdatum der betreffenden Person angegeben, der das Grabmal gilt, wie bei den früheren Beispielen, vielmehr wird eine kurze, „lapidare“ Charakteristik des Verstorbenen geboten. Genannt wird unter anderem auch die von dem Grafen veranlasste Reformation der Grafschaft. Er wird bezeichnet als ... recuperati Evangelii primus apud suos, non parvis obiectis periculis defensor et instaurator...

Es findet also hier ein nicht nur durch den Humanismus, sondern auch durch die Reformation veranlasster Rückgriff auf antike Vorbilder statt. Memoria wird neu gefasst, sie findet nicht mehr gottesdienstlich statt durch eine von Stiftungen unterhaltene Gemeinschaft von Mönchen oder Klerikern, sondern durch eine Anrede an das Publikum - zumindest soweit es des Lateinischen mächtig ist - durch eine beständige Erinnerung an Persönlichkeit und Verdienste des Verstorbenen. Es ist also die fama im Sinne des vierten Gesangs von Vergils Aeneis ${ }^{65}$, die das Fortleben im Gedächtnis der Nachwelt sicherstellen soll.

Im gleichen Geist wie das Grabmal Georgs II. ist das für seinen Vater Michael II. $(† 1531)$ gehalten $^{66}$. Hier sind die Verdienste freilich anderer Gestalt: Michael II. tat sich hervor durch die Befestigung der Burg Breuberg, als Friedenswahrer und angesehener Schiedrichter. Dieses Grabmal nennt auch dessen Schöpfer und wohl den Tag der Fertigstellung: Perme Christophorum statuarium 1543 Sept. 24. Es handelt sich um den Meister, den die Kunstgeschichte als „Christoph von Urach“ bezeichnet, nach seinem Hauptwerk, dem Taufstein in der Uracher Amanduskirche ${ }^{67}$.

Graf Michael II. ist allerdings in der Kirche in Sandbach bestattet. Offenbar dokumentiert sich darin seine enge Verbindung mit der Herrschaft Breuberg. In derselben Kirche ist auch sein Enkel Michael III. (1529-1556), der Letzte seines Ge-

63 Hermann Ehmer, Johann Eberlin von Günzburg in Wertheim, in: WJb 1983, S. 55-71. Christian Peters, Johann Eberlin von Günzburg, ca. 1465-1533. Franziskanischer Reformer, Humanist und konservativer Reformator, Gütersloh 1994.

64 KDM Wertheim (wie Anm. 11) Nr. 6, S. 259; DI 1 (wie Anm. 11) Nr. 214, S. 88-90.

65 Vergilius, Aeneis IV, 173-190.

66 KDM Wertheim (wie Anm. 11) Nr. 5, S. 258f.; DI 1 (wie Anm. 11) Nr. 215, S. 90 f.

67 Hans-Dieter Ingenhoff, Der Taufstein des Christoph von Urach, in: Die Amanduskirche in Bad Urach, hg. von Friedrich ScHmid, Sigmaringen 1990, S. 111-119. 
schlechts, beerdigt (Abb. 7). Es handelt sich hier um ein figürliches Grabmal mit einer Inschrift in Hexametern, die Bildung, Rechtgläubigkeit und Friedensliebe des jung verstorbenen Grafen hervorheben ${ }^{68}$. Neben diesem Grabmal befand sich in derselben Kirche noch ein einfacher Grabstein, der offenbar die Stelle des Begräbnisses bezeichnete, aber beim Abbruch der alten Sandbacher Kirche 1787 verloren gegangen ist ${ }^{69}$.

Michael III. erscheint auch auf dem sogenannten Ebersteinschen Grabmal in der Stiftskirche in Wertheim ${ }^{70}$. Dieses stellt die Gräfin Katharina von Stolberg mit ihren beiden Kindern dar, zusammen mit ihrem ersten Ehemann, Graf Michael III. von Wertheim, und ihrem zweiten Ehemann, Graf Philipp von Eberstein. Die Inschrift, die Michael III. gilt, stellt ein kunstvolles Wechselgespräch dar. Gefragt wird nach Person und Tugenden des Verstorbenen, die ein Genius in knappen Worten darstellt.

Das Ebersteinsche Grabmal zeigt den Dynastienwechsel in Wertheim an. Katharina von Stolberg wurde von ihrem Vater Ludwig von Stolberg beerbt, dessen anderer Schwiegersohn Graf Ludwig von Löwenstein (†1611) nach vielen Auseinandersetzungen schließlich den Kern des Wertheimer Erbes überkam und eine neue Dynastie und damit auch ein neues Gedächtnis in der Wertheimer Stiftskirche begründete. Das Hochgrab des Grafen Johann I. (1372-1407) in der Mitte des Chors wurde 1618 abgeräumt, die Grabplatte an die Chorwand versetzt und dafür das prunkvolle Freigrab für den Grafen Ludwig und die Gräfin Anna von Stolberg errichtet $^{71}$. Damit hatte die neue Dynastie in der Mitte des Chores Platz genommen und sich in die Mitte des allgemeinen Bewusstseins gerückt.

Zusammenfassend kann gesagt werden, dass die Memoria der Grafen von Wertheim in den üblichen mittelalterlichen Formen des gottesdienstlich-liturgischen Gedächtnisses gehalten war. Dafür wurden Stiftungen zugunsten von Mönchsund Klerikergemeinschaften gemacht, die je nach zeitbedingten Vorlieben wechselten, beginnend mit der Zisterze Bronnbach und der Kartause Grünau und schließlich dem Stift Wertheim. Ihr Ende fanden diese Formen der Memoria durch die Reformation. Es handelte sich freilich nur um einen Wandel der Ausdrucksformen, da neue Formen der Memoria, der Vergegenwärtigung der Verstorbenen eingerichtet wurden. Die Monumentalinschriften der nunmehr geschaffenen Grabmäler waren freilich keine Neuschöpfung, sondern stellen ein Aufgreifen antiker Vorbilder dar. Bald fand allerdings auch eine Rückkehr zum bildlichen Grab-

${ }^{68}$ Kunstdenkmäler im Großherzogtum Hessen, A: Provinz Starkenburg, Kreis Erbach, bearb. von Georg Schaefer, Darmstadt 1891, S. 232-234; Graf Michael III. von Wertheim (1529-1556), in: Kirchen im Breuberger Land. Sandbach, Wald-Amorbach, Höchst 1992, S. 74-89, hier besonders S. $74 \mathrm{f}$. und $88 \mathrm{f}$.

69 Daniel Schneider, Vollständige hochgräfliche Erbachische Stammtafel, nebst denen Erklär- und Bewährungen oder hochgräfliche Erbachische Historie, Frankfurt a.M. 1736, S. 579 f.; danach Aschвасн, Urkundenbuch (wie Anm. 29) S. 375.

70 KDM Wertheim (wie Anm. 11) Nr. 7, S. 259 f.; DI 1 (wie Anm. 11) Nr. 276, S. 114-116.

${ }^{71}$ KDM Wertheim (wie Anm. 11) Nr. 14, S.262f. 
mal statt, das den Verstorbenen mindestens in Lebensgröße, mit den Insignien seines Standes vorstellte. Hinzu kommen auch noch Leichenpredigten und andere Funeralien.

Die Leichenfeier für den Grafen Georg, die Eberlin von Günzburg an dem auf den Todestag folgenden Sonntag Quasimodogeniti, dem 24. April 1530, in der Wertheimer Stiftskirche veranstaltete, ist ein einzig dastehender, bemerkenswerter Versuch, hier Neues zu schaffen. Bei dieser Feier waren 19 evangelische Pfarrer und Prediger aus der Grafschaft anwesend, die die Tugenden des Verstorbenen prie$\operatorname{sen}^{72}$. Diese Veranstaltung ist, ebenso wie die ausführliche Inschrift des Grabmals, als Ansatz für eine Geschichtsschreibung zu werten, die freilich nicht unmittelbar in Gang kam.

Mit dem Kloster Bronnbach, der Kartause Grünau und der Wertheimer Stiftskirche wurden hier lediglich zentrale Orte der Memoria der Grafen von Wertheim besprochen. Das Beispiel des Grafen Asmus zeigte einen misslungenen Versuch, in der Grünsfelder Kirche einen neuen Gedächtnisort zu schaffen. Zu denken ist aber auch an andere Orte, an denen Mitgliedern des gräflichen Hauses von Wertheim gedacht wurde. In Betracht kommen hier vor allem die Söhne und Töchter des Hauses, die in ein Dom- oder Stiftskapitel, in einen Ritterorden oder in ein Kloster eintraten. Unter den nachgeborenen Söhnen finden wir Domherren in Würzburg ${ }^{73}$, Bamberg, Eichstätt, Straßburg, Mainz, Köln, Trier und Erfurt, oder an zweien oder dreien dieser Orte zugleich, ferner Stiftsherren in Aschaffenburg und Deutschordensritter, unter den Töchtern Nonnen und Äbtissinnen in Gerlachsheim, Unterzell, Schmerlenbach, Seligental, Konradsdorf und Marienborn in der Wetterau, Kirchheim im Ries und anderwärts ${ }^{74}$. Einige der Söhne gelangten zu hohen geistlichen Würden. Ein Wertheimer Graf, nämlich Albrecht, ein Sohn des Grafen Eberhard I. und Bruder Johanns I., war 1398-1421 Bischof von Bamberg. Zwei Generationen später versuchte man in einem doppelten Anlauf, einen der Söhne Johanns II. auf den Würzburger Bischofsstuhl zu bringen. Dieser Griff nach dem Bistum und dem Hochstift Würzburg misslang jedoch ${ }^{75}$. Allen diesen Mit-

72 Der Text ist überliefert im Braunen Buch der Stadt Wertheim, einer Sammelhandschrift, die vor allem chronikalische Stücke enthält. Vgl. Otto LANGGUTH, Zur Leichenfeier Graf Georgs II. von Wertheim, in: WJb 1951, S. 40-48. - Zum Braunen Buch vgl. Ehmer, Recuperati evangelii defensor (wie Anm. 58) S.215, Anm.1. - Die chronikalischen Stücke sind veröffentlicht von Erich LangGuth, „Denkwürdige Händel“ aus 200 Jahren - Die Chronik des „Braunen Buches“, in: Ders., Aus Wertheims Geschichte (wie Anm. 62) S. 141195.

${ }^{73} \mathrm{Zu}$ den Würzburger Domherren vgl.: Johann Octavian SALver, Proben des hohen Teutschen Reichs-Adels, Würzburg 1785. - Das umfangreiche Werk weist die Würzburger Domherren und gegebenenfalls auch ihre sonstigen Bepfründungen nach, ebenso wie die damals noch vorhandenen Erinnerungsstücke, wie Grabmäler und Wappen.

74 Vgl. dazu die Angaben bei: Frank Baron Freytag von Loringhoven, Europäische Stammtafeln. Stammtafeln zur Geschichte der europäischen Staaten, Bd.3, Marburg 1956, Nr. $103 \mathrm{f}$.

${ }^{75}$ Die Geschichte der beiden Stiftspfleger Johann und Albrecht von Wertheim wird aus- 
gliedern des Grafenhauses und ihren Gedächtnisorten nachzugehen, ist eine Aufgabe, die hier nicht zu leisten ist ${ }^{76}$. Gleichwohl war hier daran zu erinnern.

\section{Anhang}

Memoria als Vergegenwärtigung von Verstorbenen, als „Überwindung des Todes und des Vergessens durch,Gedächtnis‘ und ,Erinnerung““77 wird nicht nur durch fromme Stiftungen, Grabmale und Bauinschriften ins Werk gesetzt, sondern etwa auch duch die Widmung von Büchern. Im Mittelalter hat sich daraus das Widmungsbild als Typus entwickelt, das zeigt, wie der Verfasser sein Werk dem überreicht, dem er es gewidmet hat ${ }^{78}$. In der Regel ist dies ein Höhergestellter, der die Entstehung des Werks angeregt, gefördert und schließlich auch belohnt hat. Von den Grafen von Wertheim freilich ist nichts dergleichen bekannt.

Als Memoria kann aber auch die Erwähnung einer Person in profanen Texten gesehen werden, wie etwa in Wolfram von Eschenbachs Parzival, wo min herre der grave von Wertheim erwähnt wird ${ }^{79}$. Einige Textzeugen nennen sogar den Namen Poppo, gemeint ist damit Poppo II. (1183-1237). Der Zusammenhang, in dem der Graf von Wertheim im Parzival erscheint, ist der Hunger unter den Belagerten in der Festung Belrapeire. Hier wäre der Graf nicht gerne dabei gewesen, sagt der Dichter. Diese Stelle hat zu vielen unterschiedlichen, zumeist nicht haltbaren Spekulationen geführt. Einigermaßen gesichert ist immerhin, dass Wolfram als Ministerialer der Grafen von Wertheim Güter in Obereschenbach und Pleinfeld zu Lehen trug ${ }^{80}$.

Die Grafen von Wertheim werden noch mit einem anderen Dichter des Hochmittelalters in Verbindung gebracht, mit Heinrich von Veldeke (um 1140/50 - vor 1210). In der 1210-1220 entstandenen Berliner Handschrift der „Eneide“ Heinrichs findet sich in einer Illustration ein Ritter mit dem Wertheimer Wappen auf dem Schild. Es handelt sich hier immerhin um die älteste bildliche Darstellung des Wertheimer Wappens, in dem im geteilten Schild oben der wachsende Adler und

führlich beschrieben von Lorenz FRIEs, Chronik der Bischöfe von Würzburg 742-1495, Bd. 3, bearb. von Christoph Bauer u. a., Würzburg 1999, S. 218-300. Vgl. Ehmer, Geschichte (wie Anm. 10) S. 74-77.

${ }^{76}$ Einen Eindruck von der Größe dieses Forschungsfeldes gibt die umfangreiche Arbeit von Norbert Hofmann, Grafen von Wertheim im Deutschen Orden, in: WJb 1993, S. 33-88.

77 O.G. Oexle, Art. Memoria, Memorialüberlieferung, in: Lexikon des Mittelalters, Bd. 6, Stuttgart/Weimar 1999, Sp. 510-513, hier Sp. 510.

78 Vgl. J.M. Рцотzeк, Art. Dedikationsbild, in: Lexikon des Mittelalters, Bd.3, Stuttgart/Weimar 1999, Sp. $628 \mathrm{f}$.

79 Wolfram von Eschenbach, Parzival IV, 184: „... ouch was diu jaemerlîche schar elliu nâch aschen var oder alsô valwer leim. min herre der grâve von Wertheim waere ungern soldier dâ gewesen: er möhte ir soldes niht genesen."

${ }^{80}$ Ehmer, Geschichte (wie Anm. 10) S. 36-38. 
unten die drei Rosen zu sehen sind ${ }^{81}$. Hier ist freilich der Bezug zu den Grafen noch weniger deutlich, als bei Wolfram von Eschenbach.

Einem Widmungsbild näher kommt eine Illustration, die aus einer Handschrift stammt, aber leider nur als Einzelstück überliefert ist ${ }^{82}$ (Abb. 8). Es stellt zwei Männer dar, wovon der ältere als Magister Johannes de Wetflaria bezeichnet wird ${ }^{83}$, der jüngere als Dominus Johannes iunior filius insignis comitis Wertheimensis. Beide Männer sind im Disputationsgestus dargestellt, es handelt sich also nicht um ein Widmungsbild, sondern eine Illustration aus einer Handschrift. Worum es hier geht, deutet ein Spruchband an, auf dem Wetflariensis Compendium zu lesen ist. Die Spruchbänder, die den beiden Männern zugeordnet sind, wurden leider radiert; das des Johann von Wertheim ist deshalb nicht mehr zu entziffern. Immerhin dürfte so viel klar sein, dass der ältere der beiden Disputanten Dr. Johannes Lange von Wetzlar ist, ein Mediziner, der, wie eine Quittung von 1416 zeigt, in Diensten der Grafen von Wertheim stand ${ }^{84}$. Der junge Graf Johann von Wertheim ist als Geistlicher dargestellt, es handelt sich wohl um einen Sohn Johanns II. von Wertheim. Die Annahme, unter den drei Personen, die hinter dem jungen Grafen Johann stehen, sei auch dessen Vater, Graf Johann II., ist unwahrscheinlich; einen regierenden Grafen hätte man nicht in einer so nachgeordneten Stellung abgebildet. Es muss sich vielmehr um Zuhörer der Disputation handeln. Der geistliche Graf Johann brachte es zum Domdekan zu Köln und war zugleich auch Domherr zu Würzburg. In letzterer Eigenschaft wurde er 1433 Koadjutor des Bischofs von Würzburg, starb aber noch im selben Jahr $1433^{85}$.

Es war seither die Rede von solchen Fällen, in denen bewusst versucht wurde, dem Tod und dem Vergessen durch die Schaffung einer Memoria entgegenzuwirken. Schließlich ist noch auf solche Fälle zu verweisen, in denen die Memoria ursprünglich nicht intendiert war. Es handelt sich hier gewissermaßen um Überreste des Traditionsprozesses, etwa um Stücke aus dem persönlichen Besitz, die dem eigenen Gebrauch einer Person dienten und somit Rückschlüsse auf den betreffenden Menschen zulassen. Hierbei handelt es sich insbesondere um Bücher. Der einzige Graf, der uns als Buchbesitzer bekannt ist, ist Graf Asmus. In der Universitätsbibliothek Heidelberg wird ein Losbuch aus seinem Besitz verwahrt, dessen Abschrift, wie die Schlussschrift dartut, am 27. Januar 1492 in Grünsfeld in der Kanz-

81 Ehmer, Die ältesten Siegel (wie Anm. 2).

82 WJb 1924, Umschlagbild. Dazu: Haug, Zum Umschlagbild, in: ebd., S. 31 f. - Umschlagbild von E. LAngGUth, Aus Wertheims Geschichte (wie Anm. 62).

83 Vgl. zu ihm Ernst-Stephan Bauer, Frömmigkeit, Gelehrsamkeit und Zeitkritik an der Schwelle der großen Konzilien. Johannes von Wetzlar und sein Dialogus super Magnificat (1427) (Quellen und Abhandlungen zur mittelrheinischen Kirchengeschichte, Bd.39), Mainz 1981.

84 StAWt-G UN. Vgl. auch Georg Fink, Eine Wertheimer Arztbestallung von 1417, in: ZGO 68 (1914) S. 145.

85 Ehmer, Geschichte (wie Anm. 10) S. 74-77. 
lei des Grafen Asmus vollendet wurde ${ }^{86}$. Das Losbuch stellt verschiedene Wahrsagepraktiken dar und zeigt, dass Graf Asmus bei seinem an Wechselfällen reichen Leben durchaus Bedarf hatte, zumindest gelegentlich einen Blick in die Zukunft zu tun und Entscheidungshilfen zu finden.

Ein zweites Buch aus seinem Besitz ist die Handschrift eines Reisemessbuchs, das in der Ungarischen Nationalbibliothek in Budapest verwahrt wird und wohl $1500 / 1501$ entstanden ist ${ }^{87}$ (Abb. 9). Als Besitzer ist mit Wappen und Namen Graf Asmus genannt. Bei dem Messbuch handelt es sich, wie die dort wiedergegebenen Wappen dartun, offenbar um ein Geschenk von Markgraf Friedrich V. von Brandenburg (1486-1515) und dessen Gemahlin Sophia (1464-1512), einer Tochter des Königs Kasimir IV. von Polen. Das Messbuch sollte wohl dem Grafen Asmus bei einer 1501 geplanten Pilgerreise ins Heilige Land dienen. Es ist jedoch, aus uns unbekannten Gründen, nicht zu dieser Reise gekommen, worauf letzlich auch der vorzügliche Erhaltungszustand des Messbuchs schließen lässt. Gleichwohl stellen beide Bücher Elemente der Memoria dar, die auch heute noch die Vergegenwärtigung des einstigen Besitzers ermöglichen.

86 Universitätsbibliothek Heidelberg Cod. Pal. Germ. 552. Vgl. dazu Ehmer, Graf Asmus (wie Anm. 51) S. 160-163.

87 Ungarische Nationalbibliothek Budapest Cod. lat. 221. Vgl. dazu Ehmer, Graf Asmus (wie Anm.51) S.170f. 